\title{
Effects of Arm Bracing on Expiratory Flow Limitation and Lung Volume in Elderly COPD Subjects
}

\author{
Tomoyuki Ogino PT MSc, Kyoshi Mase PT PhD, Masafumi Nozoe PT PhD, Tomohiro Wada PT, \\ Yuki Uchiyama MD, Yoshihiro Fukuda MD PhD, and Kazuhisa Domen MD PhD
}

\begin{abstract}
BACKGROUND: Although it is useful for COPD patients to relieve their dyspnea by bracing their arms, the relationships between the arm bracing posture and expiratory flow limitation (EFL) and lung volume are unknown. Whether arm bracing affects dyspnea, EFL, and lung volume in elderly COPD patients was investigated. METHODS: Sixteen elderly subjects (median [interquartile range] age 81 [77-85] y) with stable COPD (percent-of-predicted FEV $_{1} 50.9$ [31.3-64.9] \%) and 16 agematched healthy subjects were studied. Breathing patterns, $\mathrm{EFL}$, lung volume, $\mathrm{S}_{\mathrm{pO}_{2}}$, and heart rate during quiet breathing were randomly evaluated in 3 standing postures: erect, leaning forward, and arm bracing. Dyspnea was also assessed for each posture with a Borg dyspnea score at the end of the test. RESULTS: Lung volume was significantly higher with arm bracing than with the other postures in both groups $(P<.05)$. Breathing patterns, $\mathrm{S}_{\mathrm{pO}_{2}}$, and pulse rate were not significantly different among the 3 postures in both groups. However, EFL and Borg dyspnea scores were significantly lower with arm bracing than with the other postures in COPD subjects $(P<.01)$. CONCLUSIONS: The decreased EFL in the arm bracing position may be caused by breathing at a higher lung volume than in the erect position, which may be one of the factors relieving dyspnea in elderly COPD patients. Key words: COPD; arm bracing posture; expiratory flow limitation; lung volume; flow-volume loop; elderly. [Respir Care 2015;60(9):1282-1287. (C) 2015 Daedalus Enterprises]
\end{abstract}

\section{Introduction}

Expiratory flow limitation (EFL) has been suggested as one factor related to exertional dyspnea in COPD patients. ${ }^{1}$ EFL, more than airway obstruction, entails a greater risk

\footnotetext{
Mr Ogino and Mr Wada are affiliated with the Department of Rehabilitation, Hyogo College of Medicine Sasayama Medical Center, Kurooka 5, Sasayama, Hyogo, Japan. Drs Mase and Nozoe are affiliated with the Department of Physical Therapy, Faculty of Nursing and Rehabilitation, Konan Women's University, Kobe, Japan. Drs Uchiyama and Fukuda are affiliated with the Department of General Medicine and Community Health Science, and Dr Domen is affiliated with the Department of Rehabilitation Medicine, Hyogo College of Medicine, Nishinomiya, Japan.
}

The authors have disclosed no conflicts of interest.

Correspondence: Tomoyuki Ogino, PT MSc, Department of Rehabilitation, Hyogo College of Medicine Sasayama Medical Center, Kurooka5, Sasayama, Hyogo, Prefecture 669-2321, Japan. E-mail: ogino0327@ yahoo.co.jp.

DOI: $10.4187 /$ respcare. 03945 of dynamic pulmonary hyperinflation, which has been recognized as an important cause of dyspnea during exercise or at rest, due to its negative effects on the work of breathing, inspiratory muscle function, and, above all, neuromechanical coupling. ${ }^{1-3}$ Since EFL is also associated with aging, 4,5 the majority of elderly COPD patients have constrained ventilation with severe EFL.

On the other hand, it is useful for COPD patients to relieve their dyspnea by bracing their arms, ${ }^{6}$ so they often do this for postural relief of dyspnea. Furthermore, studies 7,8 investigating the use of a rollator in COPD subjects consistently showed improved walking distance and less dyspnea. Mechanisms to relieve dyspnea through arm bracing have been reported to increase the activity of respiratory accessory muscles and decrease the work of breathing by taking the load off of the thorax. ${ }^{6,9,10}$ The arm bracing posture also increases lung volume. ${ }^{11,12}$ No study has investigated whether it is possible to decrease EFL by decreasing airway resistance by bracing the arms, because airway resistance depends on lung volume..$^{13}$ In the present study, whether arm bracing affects dyspnea, EFL, and lung volume was studied in elderly COPD subjects. 


\section{Methods}

\section{Subjects}

Sixteen clinically stable subjects with COPD who were receiving pulmonary rehabilitation at the Sasayama Medical Center, Hyogo College of Medicine, and who could perform spirometry according to the American Thoracic Society/European Respiratory Society task force guidelines, participated. ${ }^{14}$ The COPD subjects were clinically stable for $\geq 4$ weeks, between 64 and 88 y old, and classified as Global Initiative for Chronic Obstructive Lung Disease (GOLD) stage I-IV. The exclusion criteria were other conditions that could affect posture, walking, and dyspnea, such as heart failure or orthopedic, metabolic, or neuromuscular disorders. Sixteen age-matched healthy subjects were also studied.

This study was conducted in accordance with the amended Declaration of Helsinki. This study was approved by the ethics committee of Hyogo College of Medicine, Hyogo, Japan, and all subjects gave their written, informed consent in advance.

\section{Procedures}

All of the subjects were studied in the 3 standing postures: erect, leaning forward, and arm bracing (Fig. 1). For the arm bracing positions, the subjects leaned forward and rested their elbows on a platform whose height was set so that the subjects could assume a trunk inclination that felt most comfortable (COPD: $28.4 \pm 8.7^{\circ}$; control: $\left.24.1 \pm 7.6^{\circ}\right)$. The trunk-inclined posture had the same forward inclination of the trunk as the arm bracing position but with the arms removed from the platform. For all subjects, their FVC was first taken in the erect position. After this, all of the subjects randomly adopted 3 different postures, and their quiet breathing was measured for $30 \mathrm{~s}$ in each posture. All subjects also performed the inspiratory capacity maneuver in the erect position at the start and at the end of the measurements of the 3 positions, to correct for possible drift caused by mechanical error. ${ }^{15}$ To obtain satisfactory technique and reproducibility of the inspiratory capacity maneuvers, all subjects practiced before starting the measurements $( \pm \sim 5 \%)$. The FVC measurements were done according to the American Thoracic Society /European Respiratory Society task force guidelines. ${ }^{14}$

Lung volume and flow rate were measured by a hotwire flow meter (AE300-s, Minato Medical Science, Osaka, Japan) connected to a mouthpiece and sampled at $100 \mathrm{~Hz}$ using an analyzing system (PowerLab, ADInstruments, Dunedin, New Zealand). The data were analyzed using a Microsoft Visual Basic 6.0 program that we created.

Five stable breaths in each posture were analyzed breathby-breath, and for each subject, the duty cycle $\left(\mathrm{T}_{\mathrm{I}} / \mathrm{T}_{\text {tot }}\right)$,

\section{QUICK LOOK}

\section{Current knowledge}

Expiratory flow limitation (EFL) resulting in dynamic hyperinflation is an important cause of dyspnea in patients with COPD. Management of these patients may suggest arm bracing to relieve dyspnea; however, the relationships between the arm bracing posture and EFL and lung volume are not well described.

\section{What this paper contributes to our knowledge}

The arm bracing posture increased lung volume and decreased EFL, which decreased dyspnea in elderly COPD subjects. Arm bracing appears to cause breathing at a higher lung volume compared with the erect position, which may be one of the factors relieving dyspnea.

breathing frequency (f), tidal volume $\left(\mathrm{V}_{\mathrm{T}}\right)$, and minute ventilation $\left(\dot{\mathrm{V}}_{\mathrm{E}}\right)$ were calculated. Using the collected lung volume and flow data, the changes of EFL and lung volume in each posture were determined by superimposing a flow-volume loop of a tidal breath within a maximal flowvolume loop curve. ${ }^{15}$ The degree of EFL was expressed as the percentage of the $\mathrm{V}_{\mathrm{T}}$ over which the flow-volume loop of a tidal breath met or exceeded the maximal flow-volume loop during expiration at the same lung volume. ${ }^{15}$ End-inspiratory lung volume and end-expiratory lung volume were then normalized on the basis of FVC being $100 \%$. Subjective symptoms of dyspnea were recorded on the modified Borg scale and $\mathrm{S}_{\mathrm{pO}_{2}}$, with the pulse rate assessed using a pulse oximeter for each position measured.

\section{Statistical Analysis}

A sample size estimation using a 2-tailed test with a type- 1 error of .05 and power of $80 \%$ found that a clinically important difference in lung volume would be detected with a minimum of 16 subjects for each group. This estimation was based on a pilot study and a previous study. ${ }^{12}$

The results are shown as medians (interquartile range). $\mathrm{FEV}_{1}$ and $\mathrm{FVC}$ are expressed as percent-of-predicted values for age, sex, and height, established by the Japanese Respiratory Society. ${ }^{16}$ Comparisons of the characteristics and lung function between COPD and control subjects were performed using the Mann-Whitney $U$ test and the chi-square test. Comparisons of lung volume, breathing pattern, $\mathrm{S}_{\mathrm{pO}_{2}}$, heart rate, EFL, and the Borg dyspnea score among the 3 positions in each group were performed using the Friedman test. If significant differences were found, multiple comparisons were done by the Tukey method. 


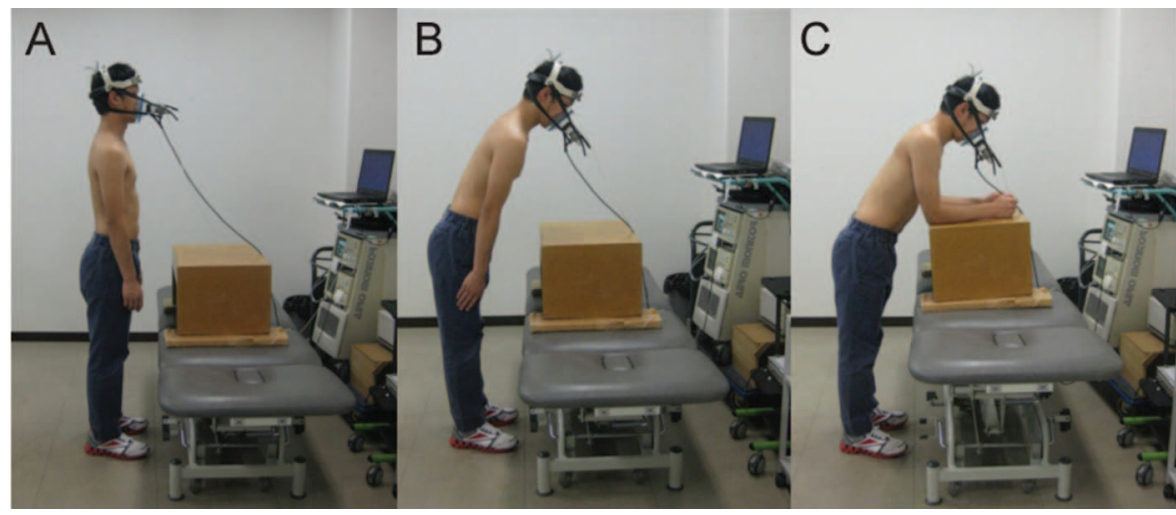

Fig. 1. Three standing postures. A: erect. B: leaning forward. C: arm bracing.

Group comparisons of lung volume, breathing pattern, $\mathrm{S}_{\mathrm{pO}_{2}}$, pulse rate, EFL, and the Borg dyspnea score were performed using the Mann-Whitney $U$ test and a Bonferroni post hoc comparison. All tests were performed at a significance level of $P<.05$. Analyses were performed with statistical software (SPSS 18, SPSS, Chicago, Illinois).

\section{Results}

Subjects' characteristics, including age, sex, height, weight, and body mass index, were not significantly different between the 2 groups. However, $\mathrm{FEV}_{1}, \mathrm{FEV}_{1} \%$, FEV/FVC, \%FVC, peak expiratory flow (PEF), and forced expiratory flow after 50 and $75 \%$ of FVC were significantly lower in COPD subjects than in control subjects (Table 1).

Figure 2 shows the changes of lung volume with each posture in both groups. Lung volume, end-inspiratory lung volume, and end-expiratory lung volume increased significantly with arm bracing compared with the other postures in both groups. However, there were no significant differences in lung volume between the 2 groups.

Table 2 shows the changes in breathing pattern, $\mathrm{S}_{\mathrm{pO}_{2}}$, pulse rate, EFL, and the Borg dyspnea score with each posture in both groups. No significant differences among postures were seen for $\mathrm{f}, \mathrm{V}_{\mathrm{T}}, \dot{\mathrm{V}}_{\mathrm{E}}, \mathrm{T}_{\mathrm{I}} / \mathrm{T}_{\mathrm{tot}}, \mathrm{S}_{\mathrm{pO}_{2}}$, and pulse rate in the 2 groups. However, EFL and the Borg dyspnea score were significantly lower with arm bracing compared with other postures in COPD subjects. In comparisons between the 2 groups, $\mathrm{V}_{\mathrm{T}}$ in the erect $(P=.002)$ and arm bracing postures $(P=.003), \dot{\mathrm{V}}_{\mathrm{E}}$ in the erect and arm bracing postures $(P=.009)$, and EFL in the erect, leaning forward $(P<.001)$, and arm bracing postures $(P=.002)$ were significantly higher only in COPD subjects.

Figure 3 shows the maximal flow-volume loop and the flow-volume loop of a tidal breath with each posture in representative cases of both groups. Breathing at low lung volume makes it easier to have EFL due to less peak expiratory flow, forced expiratory flow after $50 \%$ of FVC, and forced expiratory flow after $75 \%$ of FVC in COPD subjects than in control subjects. However, EFL decreased in the arm bracing posture because lung volume is greater than in other postures.

\section{Discussion}

The present investigation examined the changes in dyspnea, EFL, and lung volume that occur with the arm bracing posture in elderly COPD subjects. Lung volume was significantly higher with arm bracing than with the erect and leaning forward postures in both groups. This is similar to the results of previous studies. ${ }^{11,12}$ Craig ${ }^{11}$ reported that arm bracing increased expiratory reserve volume by $3.1 \%$ and that inclining the trunk forward increased it further. Prandi et $\mathrm{al}^{12}$ found that arm bracing increased functional residual volume by $300 \mathrm{~mL}$. Craig ${ }^{11}$ estimated that, by taking the load of the arms and shoulder girdles, arm bracing reduces the load on the thorax by $7-9 \mathrm{~kg}$. Furthermore, flexing the trunk is thought to change the action of gravity on the thorax, increasing its anteroposterior effect to expand the thoracic circumference, ${ }^{17}$ and, as a result, lung volume is increased.

However, EFL and Borg dyspnea scores were significantly lower with arm bracing than with the erect and leaning forward postures in COPD subjects. The decreased EFL in the arm bracing position may be caused by increasing lung volume according to the change of posture in COPD subjects. If increasing pleural pressure at the lung volume corresponding to tidal breathing induces no change in expiratory flow, EFL is seen., ${ }^{2,3}$ In addition, expiratory flow depends on the alveolar pressure and airway resistance ${ }^{18}$; the higher the lung volume is, the lower airway resistance is, ${ }^{13}$ whereas the higher the lung volume is, the more alveolar pressure rises. ${ }^{19}$ Therefore, EFL decreases at high lung volumes, which increases expiratory 


\section{EfFects of Arm Bracing on Expiratory Flow Limitation and Lung Volume}

Table 1. Characteristics and Pulmonary Function in Subjects With COPD and Healthy Controls

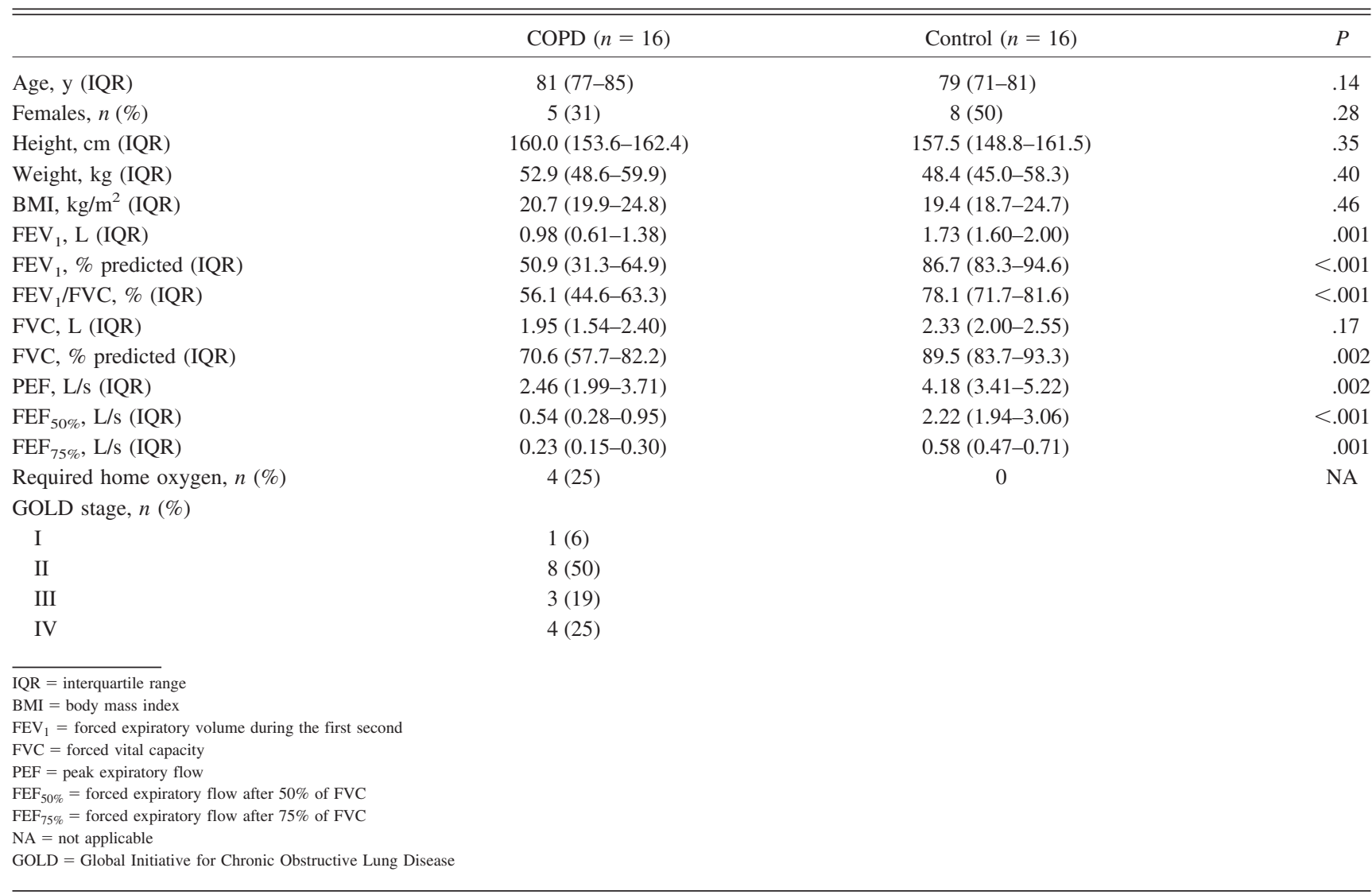

A
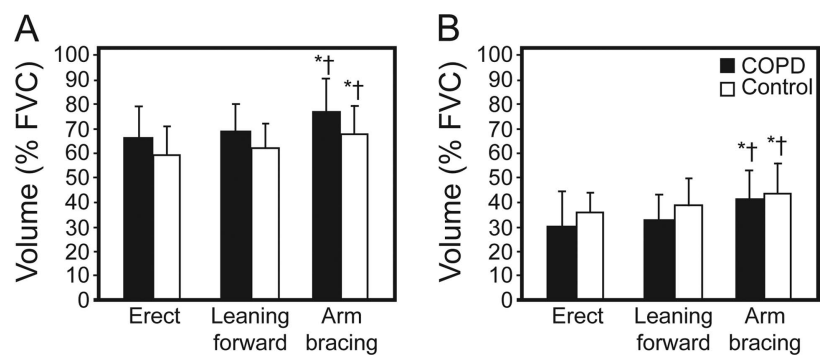

Fig. 2. Average lung volume for each posture during end-inspiratory lung volume (EILV) $(A)$ and end-expiratory lung volume (EELV) (B). ${ }^{*} P<.05$ versus erect; $\dagger P<.05$ versus leaning forward.

flow. The main factors that cause the development of EFL are linked not only to the presence of air flow reduction in the obstructive lung diseases, such as COPD, chronic asthma, cystic fibrosis, and constrictive bronchiolitis, but also to aging, body position (supine position), exercise, hyperpnea, tachypnea, and low-volume breathing, as frequently observed in patients with massive obesity and chronic congestive heart failure. ${ }^{3,15,20-23}$ From the above, we considered the possibility that the increased lung volume in the arm bracing position decreased airway resistance, and then, as a result, the EFL decreased.
Frequency, $\mathrm{V}_{\mathrm{T}}, \dot{\mathrm{V}}_{\mathrm{E}}, \mathrm{T}_{\mathrm{I}} / \mathrm{T}_{\text {tot }}, \mathrm{S}_{\mathrm{pO}_{2}}$, and the pulse rate were not significantly different among postures in both groups. Breathing patterns during the arm bracing posture were not significantly different in previous studies as well. ${ }^{10,24}$ From these results, the cause of decreased dyspnea with the arm bracing position may not be a change in breathing pattern (except for end-inspiratory lung volume, end-expiratory lung volume, and EFL), metabolic demand, and the improvement of hypoxia according to the change of posture but may instead be a decrease of EFL.

In addition, the cause of decreased dyspnea with the arm bracing position may be explained by reversal of muscle contraction. When the distal limb segment is stabilized, the proximal limb segment can be mobilized. Therefore, as the hands or forearms are stabilized, the sternum, clavicle, and rib cage can be pulled upward by the scalene, sternocleidomastoid, and pectoralis major muscles. ${ }^{9,10}$ As a result, we considered the possibility that dyspnea decreased because the inspiratory accessory muscles can work more effectively as respiratory muscles. Also, this mechanism is supported by the study of Cavalheri et al, ${ }^{25}$ which showed that the arm bracing posture increased respiratory muscle strength.

On the other hand, high-volume breathing, such as dynamic pulmonary hyperinflation, is reported to be a factor 


\section{EfFects of Arm Bracing on Expiratory Flow Limitation and Lung Volume}

Table 2. Breathing Pattern, $\mathrm{S}_{\mathrm{pO}_{2}}$, Pulse Rate, Expiratory Flow Limitation, and Borg Dyspnea Score in Various Postures

\begin{tabular}{|c|c|c|c|c|c|c|c|c|}
\hline & \multicolumn{4}{|c|}{$\operatorname{COPD}(n=16)$} & \multicolumn{4}{|c|}{ Control $(n=16)$} \\
\hline & Erect & Leaning Forward & Arm Bracing & $\begin{array}{c}P \\
\text { (ANOVA) }\end{array}$ & Erect & Leaning forward & Arm bracing & $\begin{array}{c}P \\
\text { (ANOVA) }\end{array}$ \\
\hline $\mathrm{f}$, breaths/min & $19(13-22)$ & $19(14-22)$ & $18(16-20)$ & .43 & $19(15-23)$ & $19(16-23)$ & $19(16-20)$ & .31 \\
\hline $\mathrm{V}_{\mathrm{T}}, \mathrm{L}$ & $0.77(0.64-0.90) \ddagger$ & $0.76(0.61-0.90)$ & $0.73(0.65-0.84) \ddagger$ & .78 & $0.55(0.39-0.61)$ & $0.50(0.43-0.65)$ & $0.54(0.49-0.62)$ & .44 \\
\hline$\dot{\mathrm{V}}_{\mathrm{E}}, \mathrm{L} / \mathrm{min}$ & $12.5(9.9-15.7) \ddagger$ & $13.4(10.3-15.3)$ & $13.6(10.6-15.0) \ddagger$ & .18 & $9.3(7.9-10.7)$ & $10.6(8.8-11.6)$ & $10.0(8.0-11.3)$ & .17 \\
\hline $\mathrm{T}_{\mathrm{I}} / \mathrm{T}_{\text {tot }}$ & $0.38(0.36-0.41)$ & $0.40(0.34-0.42)$ & $0.40(0.35-0.46)$ & .21 & $0.43(0.39-0.47)$ & $0.40(0.38-0.45)$ & $0.39(0.37-0.43)$ & .63 \\
\hline $\mathrm{S}_{\mathrm{pO}_{2}}, \%$ & 97 (94-98) & 97 (96-98) & 97 (95-98) & .32 & 97 (96-98) & 98 (96-98) & 98 (97-98) & .10 \\
\hline $\begin{array}{l}\text { Pulse, } \\
\text { beats/min }\end{array}$ & 77 (73-90) & $76(72-89)$ & $76(69-87)$ & .88 & $76(66-81)$ & $78(70-83)$ & $78(65-85)$ & .37 \\
\hline $\mathrm{EFL}, \%$ & $78(42-86) \neq$ & $66(46-82) \ddagger$ & $12(0-64)^{*} \dagger \dagger$ & $<.001$ & 0 & 0 & 0 & NA \\
\hline Borg dyspnea & $3(3-3)$ & $3(3-4)$ & $2(2-2)^{*} \dagger$ & $<.001$ & $2(0-3)$ & $3(0-3)$ & $2(0-3)$ & .03 \\
\hline $\begin{array}{l}\text { Data are presented a } \\
\text { ANOVA }=\text { analysis } \\
\mathrm{f}=\text { breathing freque } \\
\mathrm{V}_{\mathrm{T}}=\text { tidal volume } \\
\dot{\mathrm{V}}_{\mathrm{E}}=\text { minute ventila } \\
\mathrm{T}_{\mathrm{T}} / \mathrm{T}_{\text {tot }}=\text { duty cycle } \\
\mathrm{EFL}=\text { expiratory fl } \\
\mathrm{NA}=\text { not applicable } \\
{ }^{*} P<0.05 \text { versus el } \\
{ }^{\dagger} P<0.05 \text { versus le } \\
{ }^{*} P<0.02 \text { between }\end{array}$ & $\begin{array}{l}\text { as median (interquartile ra } \\
\text { s of variance } \\
\text { ency } \\
\text { ation } \\
\text { low limitation } \\
\text { le } \\
\text { erect } \\
\text { eaning forward } \\
\text { groups (COPD vs contro }\end{array}$ & ange). & & & & & & \\
\hline
\end{tabular}
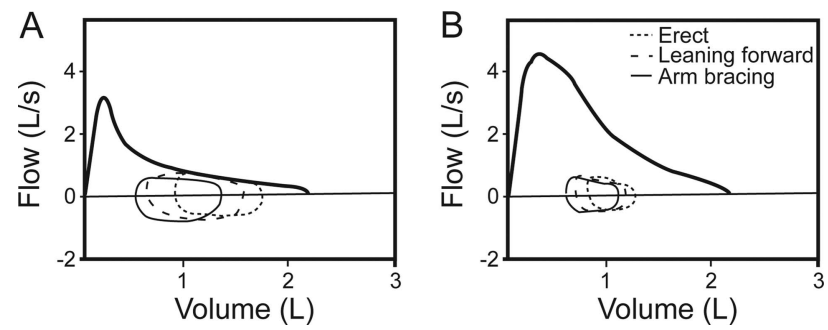

Fig. 3. Representative lung volumes and expiratory flow limitations by changing postures in COPD $(A)$ and control subjects $(B)$. The arm bracing posture results in higher lung volume than other postures in both groups; however, expiratory flow limitation decreases more in the arm bracing posture than in other postures in COPD subjects.

that limits the increase in $\mathrm{V}_{\mathrm{T}}$ due to impairment of inspiratory muscle function because the inspiratory muscles are shortened. ${ }^{1,15}$ However, the present results showed that there was no adverse effect from breathing at a higher lung volume in both groups. Therefore, breathing at a higher lung volume under these measurement conditions appeared to cause little adverse effect.

\section{Limitations}

EFL was assessed by superimposing the flow-volume loop of a tidal breath within a maximal flow-volume loop in this study. ${ }^{15}$ However, this approach has been pointed out to have some problems. ${ }^{2}$ The first is thoracic gas compression artifacts. To minimize such errors, volume should be measured with a body plethysmograph. Second, incorrect alignment of tidal expiratory flow-volume and maximal flow-volume loop curves can occur. Such alignment is usually made considering the total lung capacity as a fixed reference point. This assumption may not always be valid. Third, there is the effect of previous volume and time history. Since the previous volume and time history of a spontaneous tidal breath is necessarily different from that of an FVC maneuver, it is axiomatic that comparison of the flow-volume loop of a tidal breath with the maximal flow-volume loop curves is problematic. Fourth, the respiratory mechanics and time constant inequalities are different during the tidal and maximal expiratory efforts, also making comparisons of the 2 flow-volume curves problematic. Fifth, an important limitation of the conventional method is that it requires subject cooperation. This is not always feasible. Thus, this might have affected the assessment of EFL in this study. However, it has been shown that the arm bracing posture increases lung volume in previous studies. ${ }^{11,12}$ Therefore, the results of this study support the effects of decreased EFL with the arm bracing position.

In addition, the sample size was too small and the measurement time was too short to fully examine the relationships between the arm bracing posture and EFL and lung volume in COPD subjects. We did not study younger subjects with COPD or subjects with less severe EFL. There was also variation in the distribution of severity among the subjects. Further studies are required to address these issues. 


\section{Effects of Arm Bracing on Expiratory Flow Limitation and Lung Volume}

\section{Conclusions}

The arm bracing posture increased lung volume and decreased EFL, which decreased dyspnea in elderly COPD subjects. Therefore, the decreased EFL in the arm bracing position may cause breathing at a higher lung volume than in the erect position, which may be one of the factors relieving dyspnea in elderly COPD patients.

\section{REFERENCES}

1. O'Donnell DE, Webb KA. Exertional breathlessness in patients with chronic airflow limitation: the role of lung hyperinflation. Am Rev Respir Dis 1993;148(5):1351-1357.

2. Calverley PMA, Koulouris NG. Flow limitation and dynamic hyperinflation: key concepts in modern respiratory physiology. Eur Respir J 2005;25(1):186-199.

3. Tantucci C. Expiratory flow limitation definition, mechanisms, methods, and significance. Pulm Med 2013;2013:749860. doi: 10.1155/ 2013/749860.

4. Janssens JP, Pache JC, Nicod LP. Physiological changes in respiratory function associated with ageing. Eur Respir J 1999;13(1):197205.

5. DeLorey DS, Babb TG. Progressive mechanical ventilator constraints with aging. Am J Respir Crit Care Med 1999;160(1):169-177.

6. Sharp JT, Drutz WS, Moisan T, Foster J, Machnach W. Postural relief of dyspnea in severe chronic obstructive pulmonary disease. Am Rev Respir Dis 1980;122(2):201-211.

7. Solway S, Brooks D, Lau L, Goldstein R. The short-term effect of a rollator on functional exercise capacity among individuals with severe COPD. Chest 2002;122(1):56-65.

8. Probst VS, Troosters T, Coosemans I, Spruit MA, Pitta Fde O, Decramer M, Gosselink R. Mechanisms of improvement in exercise capacity using a rollator in patients with COPD. Chest 2004;126(4): 1102-1107.

9. Banzett RB, Topulos GP, Leith DE, Nations CS. Bracing arms increases the capacity for sustained hyperpnea. Am Rev Respir Dis 1988;138(1):106-109.

10. Kim KS, Byun MK, Lee WH, Cynn HS, Kwon OY, Yi CH. Effects of breathing maneuver and sitting posture on muscle activity in inspiratory accessory muscles in patients with chronic obstructive pulmonary disease. Multidiscip Respir Med 2012;7(1):9

11. Craig AB Jr. Effects of position on expiratory reserve volume of the lungs. J Appl Physiol 1960;15:59-61.
12. Prandi E, Couture J, Bellemare F. In normal subjects bracing impairs the function of the inspiratory muscles. Eur Respir J 1999;13(5): 1078-1085.

13. Briscoe WA, Dubois AB. The relationship between airway resistance, airway conductance and lung volume in subjects of different age and body size. J Clin Invest 1958;37(9):1279-1285.

14. Miller MR, Crapo R, Hankinson J, Brusasco V, Burgos F, Casaburi R., et al. General considerations for lung function testing. Eur Respir J 26(1):153-161, 2005.

15. Johnson BD, Weisman IM, Zeballos RJ, Beck KC. Emerging concepts in the evaluation of ventilatory limitation during exercise: the exercise tidal flow-volume loop. Chest 1999;116(2):488-503.

16. Hanamoto S, Ohsuji T, Tsuyuguchi I, Kawabata S, Kimura K. [Prediction formulas for pulmonary function tests expressed in linear and exponential form for healthy Japanese adults]. Nihon Kyobu Shikkan Gakkai Zasshi 1992;30(12):2051-2060. Article in Japanese.

17. Vellody VP, Nassery M, Druz WS, Sharp JT. Effect of body position change on thoracoabdominal motion. J Appl Physiol Respir Environ Exerc Physiol 1978;45(4):581-589.

18. Mead J, Turner JM, Macklem PT, Little JB. Significance of the relationship between lung recoil and maximum expiratory flow. J Appl Physiol 1967;22(1):95-108.

19. Harris RS. Pressure-volume curves of the respiratory system. Respir Care 2005;50(1):78-98; discussion 98-99.

20. Ferretti A, Giampiccolo P, Cavalli A, Milic-Emili J, Tantucci C. Expiratory flow limitation and orthopnea in massively obese subjects. Chest 2001;119(5):1401-1408.

21. Johnson BD, Beck KC, Olson LJ, O’Malley KA, Allison TG, Squires RW, Gau GT. Ventilatory constraints during exercise in patients with chronic heart failure. Chest 2000;117(2):321-332.

22. McClaran SR, Wetter TJ, Pegelow DF, Dempsey JA. Role of expiratory flow limitation in determining lung volumes and ventilation during exercise. J Appl Physiol 1999;86(4):1357-1366.

23. Alison JA, Regnis JA, Donnelly PM, Adams RD, Sullivan CE, Bye PT. End-expiratory lung volume during arm and leg exercise in normal subjects and patients with cystic fibrosis. Am J Respir Crit Care Med 1998;158(5):1450-1458.

24. Kera $\mathrm{T}$, Maruyama $\mathrm{H}$. The effect of posture on respiratory activity of the abdominal muscles. J Physiol Anthropol Appl Human Sci 2005; 24(4):259-265.

25. Cavalheri V, Camillo CA, Brunetto AF, Probst VS, Ramos EM, Pitta F. Effects of arm bracing posture on respiratory muscle strength and pulmonary function in patients with chronic obstructive pulmonary disease. Rev Port Pneumol 2010;16(6):887-891. 